\title{
1 The water footprint of water conservation with shade balls in California
}

2 Erfan Haghighi $^{1,2^{*}}$, Kaveh Madani ${ }^{3,4}$ and Arjen Y. Hoekstra ${ }^{5,6}$

3 'Department of Civil and Environmental Engineering, Massachusetts Institute of Technology, 4 Cambridge, MA 02139, USA

$5 \quad{ }^{2}$ Now at Department of Water Resources and Drinking Water, Swiss Federal Institute of Aquatic 6 Science and Technology, Dübendorf, Switzerland

$7 \quad{ }^{3}$ Center for Environmental Policy, Imperial College London, London SW7 1NA, UK

$8 \quad{ }^{4}$ Department of Physical Geography, Stockholm University, Stockholm, Sweden

$9{ }^{5}$ Twente Water Centre, University of Twente, 7522NB Enschede, the Netherlands

$10{ }^{6}$ Lee Kuan Yew School of Public Policy, National University of Singapore, 259772, Singapore

$11 \quad{ }^{*}$ Corresponsing author (email: erfanh@mit.edu)

This document is the accepted manuscript version of the following article: Haghighi, E., Madani, K., \& Hoekstra, A. Y. (2018). The water footprint of water conservation using shade balls in California. Nature Sustainability, 1(7), 358-360. https://doi .org/10.1038/s41893-018-0092-2 


\section{Abstract (65 words)}

The interest in quick technologic fixes to complex water problems increases during extreme hydroclimatic events. However, past evidence shows that such fixes might be associated with unintended consequences. We revisit the idea of using shade balls in the Los Angeles reservoir to reduce evaporation during the recent drought in California, and question its sustainability by revealing the water footprint of this technologic water conservation solution.

\section{Main Text (1675 words, including references and figure legend)}

The world is expected to face more frequent and intense temperature extremes and droughts in many regions throughout the 21 st century ${ }^{1}$. This will affect the spatial and temporal distribution of already scarce water resources and increase the need for water storage to mitigate seasonal water shortages, mainly due to projected increase in precipitation variability and growing municipal and irrigation water demands. However, the loss of water from openair water reservoirs due to evaporation, which amounts to $25 \%$ of the water consumed in agriculture, industries and households at the global scale ${ }^{2}$, exacerbates the water scarcity problem and makes it a big challenge for water managers to conserve water in storage facilities. This has led to a growing interest in developing new water saving technologies and engineered evaporation barriers, ranging from monomolecular films, continuous plastic covers and suspended shading covers to floating elements such as solar panels and spherical plastic balls (the so-called shade balls) ${ }^{3}$. Many efforts have been made to assess the effectiveness of these floating covers in suppressing evaporative water losses ${ }^{4,5}$. Nevertheless, the economic efficiency of such engineered practices is an open discussion, given the fact that water remains an undervalued natural resource all around the world.

The tendency to employ technology and quick fixes to solve water resources problems increases during extreme hydroclimatic events. California's severe drought recently sparked 
interest in the use of shade balls, leading to the release of more than 96 million shade balls with a diameter of 4 inches (about $100 \mathrm{~mm}$ ) into the Los Angeles (LA) reservoir (in Sylmar, California, August 2015) to prevent water quality deterioration due to algal blooms and suppress evaporative water losses. Whether these black shade balls were successful in water quality is still an open question, as some experts have hypothesized that they have the potential to adversely promote bacterial growth by creating a thermal blanket ${ }^{6}$. Nevertheless, these balls seem to have been somewhat successful in reducing evaporative water losses. The LA officials estimate that up to 300 million gallons $\left(1.15\right.$ million $\left.\mathrm{m}^{3}\right)$ per year have been conserved by the shade balls through evaporation suppression. But in a world in which water is used almost in every production process, even water conservation can be associated with some water use. So, one should ask how much water is impacted to make the shade balls. Answering this question helps us understand how substantial the water footprint of water conservation can potentially be. This is of particular importance now that the California's major drought (2011-2017) that motivated the use of shade balls is officially over, as we need to know whether the resulting net water conservation was positive or negative.

According to the Water Footprint Network, the water footprint of a product is a measure of surface water and groundwater usage for that product, in terms of water volumes consumed (evaporated or incorporated into the product) and polluted per functional unit ${ }^{7}$. Although the water footprint concept does not explicitly provide an estimate of related environmental impacts, it integrates water consumption and pollution over the entire supply chain and thus provides a broad perspective on the water consumed or polluted in the production system? ${ }^{7}$. Shade balls are made from high-density polyethylene (HDPE) plastic, the production of which requires crude oil, natural gas and electricity ${ }^{8,9}$. Extracting oil and natural gas is waterintensive as is electricity generation ${ }^{10,11}$ and thus, producing HDPE shade balls can have significant water quantity and quality impacts. Relying on the water footprint concept and 
63 focusing on water consumption alone, we can estimate the total volume of water consumed 64 for producing HDPE and thus for the shade balls.

65 Our calculations, summarized in Table 1 and Fig. 1, suggest that saving 1.15 million $\mathrm{m}^{3}$ of water a year through 96 million HDPE balls with a diameter of $100 \mathrm{~mm}$ in the LA reservoir costs 0.25 to 2.9 million $\mathrm{m}^{3}$ of water consumed for producing the balls, assuming different ball thicknesses ( 1 to $5 \mathrm{~mm}$ ) with an estimated global averaged water footprint of 0.05 to 0.19

$69 \mathrm{~m}^{3} / \mathrm{kg}_{\mathrm{HDPE}}$ (or 0.05 to 0.18 for the US). Note that the total mass of HDPE balls covering a prescribed surface area is independent of ball diameter so that the total volume of consumed water varies only with ball thickness (see the Methods section and Figs. 1a and b). Thus, the HDPE balls of a typical range of thicknesses should be on the reservoir for at least 0.2-2.5 years to have a positive net conservation and to make the balls a rational solution (see Fig. 1c). Otherwise, saving one drop of water in LA means consuming more than one drop of water in other parts of the US or globe (given the close relation between energy production and water shortages worldwide ${ }^{12}$ ) that would make this remedy unintelligent and unfair. When the HDPE balls are produced locally, the local water gain (through suppressing evaporative water losses) would be partially or even fully offset by local water consumption for producing the HDPE balls.

Applying lightweight balls with smaller thicknesses can reduce the total weight of balls (and thus the total volume of water consumed) per area of covered surface, but they are subject to operational difficulties, being less stable and prone to move. This would expose the water already warmed up due to the thermal blanket effect, resulting in higher evaporation rates from uncovered patches (with higher surface water temperature) and ultimately hindering shade ball application as an effective water saving solution. Overall, assuming that HDPE balls have quite a long lifetime and are not hard to maintain, they might be worth their water 
87 footprint for "long-term" water saving purposes. Nevertheless, the problem can get more complicated if one considers other environmental impacts of the shade balls from a life cycle perspective ${ }^{13}$, such as water quality (e.g., water polluted for producing HDPE balls or the thermal blanket effect adversely promoting bacterial growth in the reservoir), ecology and life in the reservoir (affected by changes in water temperature, light penetration and oxygen transfer), production and transportation energy and carbon emissions, in addition to their costs (construction and annual maintenance) and consumptive water footprint.

Humans have already noticed how technologic and rushed solutions to water shortage (drought) or excess (flooding) could create secondary environmental and economic impacts $^{14,15}$. Thus, technologic solutions to water resources management problems arising during extreme events should be carefully motivated, particularly in the absence of integrated sustainability assessment analyses that can reveal the likely adverse environmental and/or socioeconomic impacts of such water management practices. Our analysis underlines the importance of the need for a comprehensive assessment of the shade balls solution in California. Our results show that even water conservation is associated with some water footprint that can make the conservation solution questionable. Based on our analysis, the water consumption associated with producing shade balls of a typical thickness of $5 \mathrm{~mm}$ was larger than the reduced reservoir evaporation achieved by the balls in the 1.5 -year period between the release of the balls (August 2015) and the end of California's major drought (March 2017). Without considering the practical challenges of maintaining a constant performance efficiency and assuming the water saving rate of 1.15 million $\mathrm{m}^{3}$ per year in the LA reservoir during the drought event remains the same outside the dry period, the balls are expected to have a positive net conservation from February 2018 (i.e., after 2.5 years). Nevertheless, the continued presence of the balls during wetter periods, when evaporation rates are relatively lower, should be justified, as the local modifications to water surface 
112

113

114

115 or Table 1. volume.

energy balance in the presence of floating covers (i.e., increase in surface water temperature and/or air temperature in contact with water gaps) are likely to reduce their evaporation suppression efficiency ${ }^{5}$ and even enhance evaporative water losses under cold temperatures (i.e., zero or negative efficiency) ${ }^{16}$.

\section{Methods (152 words)}

The (consumptive) water footprint of HDPE balls. The balls are made from high-density polyethylene (HDPE), a solid fossil fuel transformed using crude oil, natural gas and electricity $^{8,9}$. Given the blue water footprint of these natural resources reported in the literature $^{10}$, we estimate the water footprint $(W F)$ of HDPE balls as $0.05-0.19 \mathrm{~m}^{3} / \mathrm{kg}_{\mathrm{HDPE}}$. The total volume of water consumed for producing HDPE balls in the LA reservoir $\left(V_{w, t}\right)$ was estimated as $V_{w, t}=M_{b, t} \times W F$ where $M_{b, t}=N_{b} \times V_{b, s} \times \rho_{H D P E}$ is the total weight of shade balls, with $\rho_{\text {HDPE }}=930-970 \mathrm{~kg} / \mathrm{m}^{3}$ the density of HDPE, and $V_{b, s}=4 \pi r_{b}^{2} t$ the (solid) volume of a spherical shell with outer radius $r_{b}$ and thickness $t$ (for $t$ much less than $r_{b}$ ). $N_{b}=\lambda \times\left(A \times 2 r_{b}\right) / V_{b}=\lambda \times 3 A / 2 \pi r_{b}^{2}$ is the total number of spherical shade balls covering the reservoir, with $A \approx 710000 \mathrm{~m}^{2}$ the LA reservoir's surface area and $\lambda(-)$ is the sphere packing density ranging from 0.64 to 0.74 , respectively, for random and cubic/hexagonal close packing $^{17}$ of spherical balls of $V_{b}=4 \pi r_{b}^{3} / 3$ volume in a (virtual) box of $\left(A \times 2 r_{b}\right)$

Data availability. The data supporting the findings of this study are provided in the main text 
134 1. Dai, A. Nat. Clim. Chang. 3, 52-58 (2013).

2. Hogeboom, R.J., Knook, L. \& Hoekstra, A.Y. Adv. Water Resour. 113, 285-294 (2018).

3. Craig, I.P. Loss of Water Storage Due to Evaporation - A Literature Review (Univ. South Queensland, NCEA, 2005).

4. $\quad$ Assouline, S., Narkis, K. \& Or, D. Water Resour. Res. 47, W07506 (2011).

5. Aminzadeh, M., Lehmann, P. \& Or, D. Hydrol. Earth Syst. Sci. Discuss. 1-45 (2017).

6. de Graaf, M. Daily Mail (20 August 2015); http://www.dailymail.co.uk/news/article3204873/How-100-million-shade-balls-brought-protect-LA-s-reservoir-evaporatingfact-bacterial-nightmare.html

7. Hoekstra, A.Y., Chapagain, A.K., Aldaya, M.M. \& Mekonnen, M.M. The Water Footprint Assesment Manual: Setting the Global Standard (Earthscan, 2011).

8. Boustead, I. Eco-Profiles of the European Plastics Industry: High Density Plyethylene (HDPE) (Plastics Europe, 2005).

9. Feraldi, R. et al. Cradle-to-Gate Life Cycle Inventory of Nine Plastic Resins and Four

Polyurethane Presursors (Franklin Associates, Eastern Research Group Inc., 2011).

10. Mekonnen, M.M., Gerbens-Leenes, P.W. \& Hoekstra, A.Y. Environ. Sci. Water Res. Technol. 1, 285-297 (2015).

11. Madani, K. \& Khatami, S. Curr. Sustain. Energy Reports 2, 10-16 (2015).

12. Holland, R.A. et al. Proc. Natl. Acad. Sci. 112, E6707-E6716 (2015).

13. Hellweg, S. \& Milà i Canals, L. Science 344, 1109-13 (2014).

14. Gohari, A. et al. J. Hydrol. 491, 23-39 (2013).

15. Mirchi, A., Watkins, D. \& Madani, K. in Watersheds: Management, Restoration and Environmental Impact (ed. Vaughn J. C.) 221-244 (Nova Science Publishers, 2010).

16. Mady, B., Lehmann, P. \& Or, D. Geophys. Res. Abstr. EGU Gen. Assem. 20, 11778 (2018).

17. Jaeger, H.M. \& Nagel, S.R. Science 255, 1523-1531 (1992). 
163 Corresponding author

164 Correspondence and requests for materials should be addressed to E.H. (email:

165 erfanh@mit.edu)

166 Acknowledgements

167 E.H. acknowledges funding from Swiss National Science Foundations (SNSF grant No. 168 P2EZP2-165244).

169 Author contributions

170 E.H. and K.M. conceived and designed the study. All authors performed the research, 171 analyzed data and wrote the paper.

\section{Competing interests}

173 The authors declare no competing interests. 
174 Fig. 1: (a) Total number of HDPE shade balls of different diameters $\left(2 r_{b}\right)$ to cover the LA 175 reservoir of surface area $A \approx 710000 \mathrm{~m}^{2}$. Note opposite variations in total number of balls 176 and their unit weight with ball diameter such that total mass of HDPE balls covering a given 177 surface area becomes independent of ball diameter and varies only with ball thickness (i.e., $\left.178 M_{b, t}=6 \lambda A \rho_{H D P E} t\right)$-see the Methods section. (b) Total volume of water consumed for 179 producing the balls $\left(V_{w, t}=M_{b, t} \times W F\right)$, with water footprints (WF) ranging from 0.05 to 0.19 $180 \mathrm{~m}^{3} / \mathrm{kg}_{\mathrm{HDPE}}$, for a typical range of ball thicknesses (independent of ball diameter). Presented 181 also is the water payback period of the HDPE balls (c), i.e. the number of years before the net 182 conservation becomes positive, given the estimated water conservation of 1.15 million $\mathrm{m}^{3}$ per 183 year in the LA reservoir. 
Table 1. Total volume of water consumed for producing $1000 \mathrm{~kg}$ of HDPE

\begin{tabular}{llll}
\hline Energy sources $^{8,9}$ & $\begin{array}{l}\text { Total energy } \\
\text { (material and process energy) }\end{array}$ & $\begin{array}{l}\text { Water footprint } \\
\left(\mathrm{m}^{3} / \mathrm{GJ}\right)^{*}\end{array}$ & $\begin{array}{l}\text { Volume of water } \\
\text { consumed }\left(\mathrm{m}^{3}\right)^{*}\end{array}$ \\
\hline Crude oil & $10.1-41.0$ & $0.21-1.19$ & $2.1-48.8$ \\
Natural gas & $30-60$ & $0.08-1.24$ & $2.4-74.4$ \\
Electricity & $4-9$ & $4.24(2.50)$ & $17-38.2(10-22.5)$ \\
\hline & Water for energy sources & $21.5-161.4(14.5-145.7)$ \\
& & Water for processing and cooling & 32.0 \\
\hline
\end{tabular}

*Values are global averages, except those in brackets that are US-specific data. 


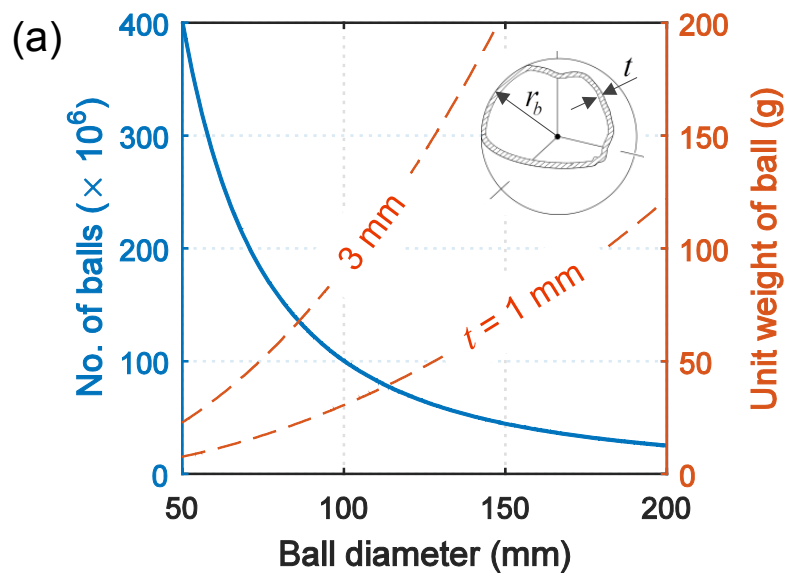

(b)

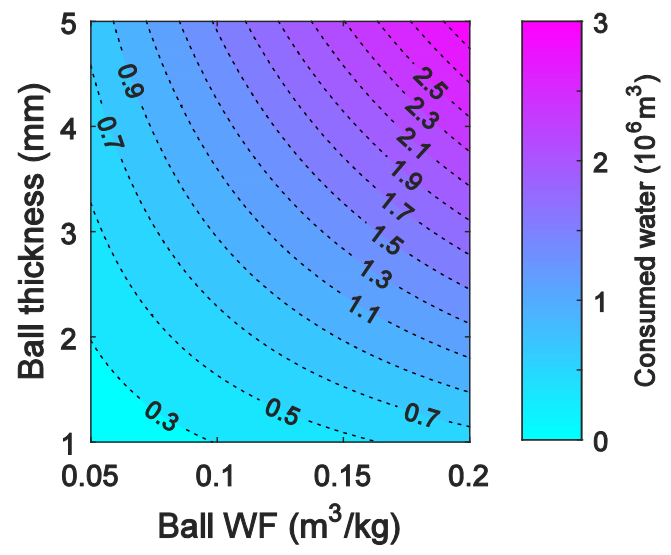

(c)
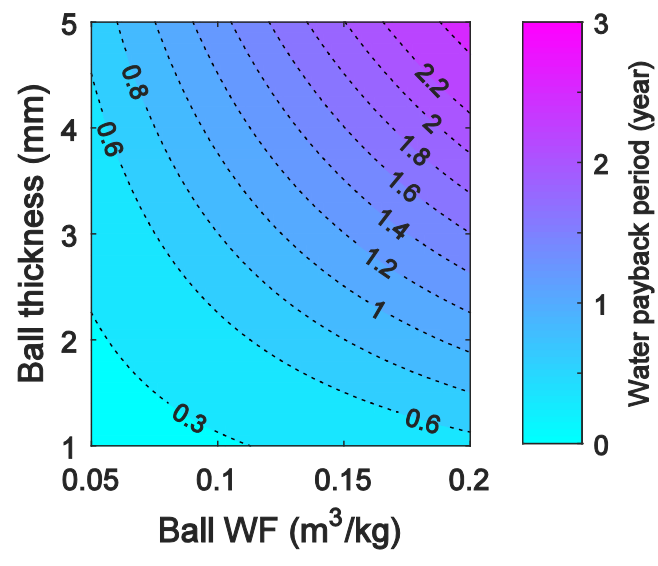